\title{
Avaliação das perdas de líquido por degelo de frangos congelados (Drip Test) em abatedouros*
}

\section{Drip losses evaluation in frozen chickens (Drip Test) at abattoirs}

\author{
Maria Fernanda Garnica, ${ }^{* *}$ Gabriel Augusto Marques Rossi, ${ }^{* *}$ Ana Carolina Siqueira Gonçalves, ${ }^{* *}$ \\ Carlos Eduardo Gamero Aguilar, ${ }^{* *}$ Henrique Meiroz de Souza Almeida, ${ }^{* *}$ Ana Maria Centola Vidal Martins ${ }^{\star * *}$
}

\begin{abstract}
Resumo
Este trabalho objetivou avaliar a quantidade de água resultante do descongelamento de carcaças de aves oriundas de quatro abatedouros de aves no estado de São Paulo, sob Serviço de Inspeção Estadual, através do método Drip Test, durante os anos de 2011 e 2012. Foram utilizadas 45 amostras, sendo que cada uma dessas era composta por seis carcaças de frango congeladas, determinando um total de 270 carcaças de aves utilizadas. Durante a realização do estudo, apenas 4,44\% (2/45) das amostras apresentaram valores acima do limite aceitável determinado pelo Ministério da Agricultura, Pecuária e Abastecimento (MAPA), sendo que essas pertenciam a abatedouros distintos, porém não foi observada diferença significativa entre todos os estabelecimentos avaliados. Pode-se concluir que 4,44\% das amostras do monitoramento apresentaram-se fora do padrão legal, oriundas de falhas tecnológicas e que resultam na insatisfação dos consumidores. É necessário um monitoramento de rotina, com colheita de amostras prontas para a comercialização sem prévio aviso, como prática a salvaguardar os interesses dos consumidores e à coibição de fraudes intencionais, principalmente naqueles estabelecimentos que evidenciem valores frequentemente elevados.
\end{abstract}

Palavras-chave: aves domésticas, fraude comercial, inspeção sanitária de produtos de origem animal, qualidade de carne.

\begin{abstract}
This study aimed to evaluate the amount of water resulting from poultry carcasses from four slaughterhouses at the São Paulo State, Brazil, through "Drip Test" method, during the years 2011 and 2012. It was used 45 samples, which were consisted of 6 chicken frozen carcasses, totalizing 270 chickens. During the study, 4.44\% (2/45) of the samples had values above the acceptable limit by Ministry of Agriculture, Livestock and Supply (MAPA), and were from two different establishments, but was not observed significant difference among all the establishments. It was concluded that some samples were not in concordance with legal standards, arising from technological failures that contributes to cause consumer dissatisfaction. Is necessary a routine monitoring system, utilizing samples ready for commercialization without previously notice, to safeguard the consumer's interests and avoid intentional fraud, especially in those establishments that commonly presents high values.
\end{abstract}

Keywords: commercial fraud, meat quality, poultry, sanitary inspection of animal products.

\section{Introdução}

A produção avícola brasileira vem-se destacando no cenário mundial. Somente no ano de 2012, o Brasil produziu 12,65 milhões de toneladas de carne de frango, sendo o estado de São Paulo responsável pelo abate de $12,86 \%$ desses animais. O consumo desse alimento também vem crescendo nos últimos anos em nosso país. Até o ano 2000 eram consumidos em média menos de 30 quilos anualmente por pessoa, mas no ano de 2012 esse valor anual de consumo atingiu o valor de 45 quilos (UBABEF, 2013).

O tema qualidade quando aplicado às indústrias desse tipo de alimento é amplo e diverso, e, embora haja tendência em se privilegiar os aspectos relativos à segurança, deve-se considerar também o conjunto de características que atendam à demanda e expectativa dos consumidores, os quais buscam produtos íntegros, não fraudados e que satisfaçam suas necessidades. Esses consumidores frequentemente reclamam do grande volume de líquido produzido no descongelamento das carnes de aves (IDEC, 2005).

Durante o processo de abate de aves, as carcaças são resfriadas por imersão em água potável refrigerada. Nesse processo, as carcaças entram no "pré-chiller" contendo água a, no máximo, $4^{\circ} \mathrm{C}$ e deve sair no "chiller" final contendo também água a, no máximo, $16^{\circ} \mathrm{C}$ (Brasil, 1998). Com o objetivo de controlar tal situação e coibir a prática de fraude pelos estabelecimentos processadores, visto que as carcaças ganham peso quando submetidas a tal processamento de resfriamento (James et al., 2006), estabeleceu-se o Drip Test (DT), que visa determinar a quantidade de água absorvida durante o processo industrial.

O Regulamento Técnico de Inspeção Tecnológica e HigiênicoSanitária de Carnes de Aves contempla a metodologia a ser utilizada nesse teste, que é utilizado para determinar a quantidade de água resultante do descongelamento de carcaças congeladas. Se a quantidade de água resultante, expressa

\footnotetext{
*Recebido em 14 de novembro de 2013 e aceito em 17 de março de 2014.

**Depto. de Medicina Veterinária Preventiva e Reprodução Animal, Universidade Estadual Paulista “Julio de Mesquita Filho", Faculdade de Ciências Agrárias e Veterinárias de Jaboticabal, São Paulo, Brasil.

***Depto. de Medicina Veterinária, Universidade de São Paulo, Faculdade de Zootecnia e Engenharia de Alimentos de Pirassununga, São Paulo, Brasil.
} 
em percentagem do peso da carcaça, com todas as partes comestíveis na embalagem, ultrapassar o valor limite de $6 \%$, considera-se que a carcaça absorveu um excesso de água durante o pré-resfriamento por imersão em água, podendo ser considerada uma fraude (Brasil, 1998).

Não são raras as situações em que são encontradas amostras acima dos limites aceitáveis, conforme descrito por Negrini et al. (2007), Sá et al. (2007), Gomes e Azeredo (2009) e Machado et al. (2012), que encontraram amostras fora do padrão legal em diferentes estados federativos brasileiros e em diferentes períodos históricos.

O presente trabalho objetivou avaliar a quantidade de água resultante do descongelamento de carcaças de aves oriundas de quatro abatedouros no estado de São Paulo, sob Serviço de Inspeção Estadual, através do método Drip Test durante os anos de 2011 e 2012.

\section{Material e métodos}

O trabalho foi realizado em quatro abatedouros de aves localizados no estado de São Paulo, todos cadastrados no Serviço de Inspeção Estadual (SISP). Foram colhidas amostras mensais durante todo o ano de 2011 e durante o primeiro semestre de 2012, com pelo menos dez meses não sequenciais de cada estabelecimento. Cada amostra coletada era formada por seis carcaças de aves congeladas e mantidas $a-12^{\circ} \mathrm{C}$ até o momento da análise. O Drip Test (DT) foi realizado em um total de 270 carcaças, totalizando 45 amostras $(n=45)$.

A execução dos testes na amostragem foi realizada no Laboratório Nacional Agropecuário - Lanagro/SP, utilizando a metodologia preconizada por Brasil (1998). Essa consiste em: 1) secagem do lado externo da embalagem de modo a eliminar todo o líquido e gelo, seguida da pesagem da amostra $\left.\left(\mathrm{M}_{0}\right) ; 2\right)$ retirada da ave congelada de dentro da embalagem (com as respectivas vísceras), seguida de nova secagem (enxugamento) da embalagem, com sua pesagem $\left(M_{1}\right) ; 3$ ) ave abatida (produto testado) mais as respectivas vísceras foram colocadas dentro de uma embalagem plástica com a abertura no abdômen da ave voltado para o fundo da embalagem, com posterior imersão do conjunto em banho de água a temperatura de $42^{\circ} \mathrm{C}$ até que a temperatura do centro da ave atingisse $4^{\circ} \mathrm{C}$. Para a determinação do tempo de imersão, foi utilizada a tabela preconizada no Regulamento Técnico de Inspeção Tecnológica e Higiênico-Sanitária de Carnes de Aves, Portaria № 210, de 10 de novembro de 1998; 4) após o período de imersão, a amostra foi removida do banho de descongelamento, 5) tal embalagem foi cuidadosamente aberta com a realização de um orifício na parte inferior, de modo que a água liberada pelo descongelamento pudesse escorrer por uma hora à temperatura ambiente entre 18 e $25^{\circ} \mathrm{C}$; 6) retirada da ave e das vísceras descongeladas da embalagem, com coleta do líquido escoado; 7) procedeu-se ao enxugamento das vísceras; 8) ave descongelada e respectivas vísceras foram pesadas conjuntamente, além da pesagem da embalagem $\left(\mathrm{M}_{2}\right)$; e 9 ) também foi pesada a embalagem que continha as vísceras $\left(\mathrm{M}_{3}\right)$. O cálculo da porcentagem de líquidos perdidos no descongelamento foi realizado pela fórmula $\left(M_{0}\right.$ $\left.M_{1}-M_{2} / M_{0}-M_{1}-M_{3}\right) \times 100$. Os resultados foram considerados inaceitáveis, ultrapassando o valor limite, quando a quantidade média de água resultante do descongelamento de cada amostra (composta por seis carcaças) foi superior a 6\% (Brasil, 1998).
As proporções de carcaças com DT $>6 \%$ observadas nos diversos abatedouros foram comparadas entre si por meio do teste de qui-quadrado ou do teste exato de Fisher, quando fosse o caso, adotando o nível de significância de $95 \%$ (a = $0,05)$. Essas análises foram efetuadas usando o software $R(R$ CORE TEAM, 2013).

\section{Resultados e discussão}

Os resultados do DT nas 45 amostras obtidas dos quatro abatedouros foram agrupados e encontram-se na Tabela 1.

Tabela 1: Resultados das amostras através do Drip Test (DT) de carcaças de aves abatidas durante os anos de 2011 a 2012 em quatro estabelecimentos registrados no SISP

\begin{tabular}{cccc}
\hline Abatedouro & $\begin{array}{c}\text { Amostras } \\
\text { (n) }\end{array}$ & $\begin{array}{c}\text { Amostras } \\
\text { DT }>\mathbf{6 \%} \\
\text { (n) }\end{array}$ & $\begin{array}{c}\text { Amostras } \\
\text { DT >6\% } \\
\text { (\%) }\end{array}$ \\
\hline A1 & 13 & 1 & $7,69^{\mathrm{a}}$ \\
A2 & 10 & 0 & $0^{\mathrm{a}}$ \\
A3 & 12 & 0 & $0^{\mathrm{a}}$ \\
A4 & 10 & 1 & $10^{\mathrm{a}}$ \\
Total & 45 & 2 & 4,44 \\
\hline
\end{tabular}

Letra igual na coluna indica diferença não significativa pelo teste exato de Fisher.

Durante a realização do estudo, apenas $4,44 \%(2 / 45)$ das amostras apresentaram valores acima do limite aceitável, sendo que pertenciam a estabelecimentos distintos, conforme pode ser observado na Tabela 1. Destaca-se que a amostragem formada por seis carcaças preconizada pelo MAPA para realização do DT apresenta bons resultados, semelhantes comparativamente a quando se utilizam 12 carcaças (Santos et al., 2013).

Esses resultados observados demonstram a presença de falhas tecnológicas nos abatedouros A1 e A4, na etapa de pré-resfriamento das carcaças, que acarretam em absorção de água acima dos limites aceitáveis, e consistem em práticas de fraude comercial quando esses produtos chegam ao alcance dos consumidores. Entretanto, não pode ser observada diferença significativa $(p \geq 0,05)$ entre os quatro estabelecimentos.

Segundo Carciofi e Laurindo (2007), a absorção de água pelas carcaças de aves durante o resfriamento por imersão é influenciada por fatores como temperatura, pressão hidrostática, agitação da água no tanque e o tempo de imersão das carcaças, os quais necessitam tornar-se adequados nas duas indústrias supracitadas.

A ocorrência de amostras com absorção de água acima do limite permitido também apresenta relação com a ocorrência de carne PSE (Pale, Soft and Exsudative), conforme demonstrado por Kato et al. (2013), que observou maior perda de líquidos em carnes classificadas como PSE.

Negrini et al. (2007) realizou avaliação dos frangos disponíveis para população no município de Campo Grande e relatou que os valores observados encontravam-se acima do limite permitido, evidenciando a ocorrência de fraude comercial em produtos ofertados à população. Sá et al. (2007), avaliando carcaças congeladas de frangos oriundos de quatro abatedouros 
obtidas em supermercados de Uberlândia/MG, encontraram irregularidades de excesso de absorção de água pelo DT em dois dos estabelecimentos.

Também Machado et al. (2012) avaliaram 5 diferentes marcas de frango congelado disponíveis à venda na cidade de Londrina/ $\mathrm{PR}$, das quais $3(60 \%)$ apresentaram valores acima do limite aceitável. Ainda, Gomes e Azeredo (2009) avaliaram 47 amostras de frangos congelados comercializados no município de Rio de Janeiro/RJ nos anos de 2004 a 2005, através do DT, das quais $68 \%$ apresentaram valores acima do permitido, valor superior ao observado nesse estudo $(4,44 \%)$, possivelmente pelos estudos serem executados em períodos distintos e ter ocorrido melhorias tecnológicas nas indústrias e órgãos fiscais. Tais dados corroboram com o presente estudo, demonstrando

\section{Referências}

BRASIL. Ministério da Agricultura Pecuária e Abastecimento. Portaria $n^{\circ} 210$, de 10 de novembro de 1998, que aprova o Regulamento Técnico de Inspeção Tecnológica e HigiênicoSanitária de Carnes de Aves e estabelece as metodologias de análises e seus parâmetros, apresentando como atividade básica do Serviço de Inspeção Federal (SIF). 1998. Diário Oficial da União, 10 de novembro de 1998.

CARCIOFI, B. A. M.; LAURINDO, J. B. Water uptake by poultry carcasses during cooling by water immersion. Chemical Engineering and Processing, v. 26, p. 444-450, 2007.

GOMES, V. L. M.; AZEREDO, D. P. Avaliação do teor de água em frangos congelados comercializados no Rio de Janeiro, pelo método de gotejamento (Drip Test). Revista Higiene Alimentar, v. 23, n. 168/169, p.138-145, 2009.

IDEC, Instituto Brasileiro de Defesa do Consumidor. Excesso de água nas aves. Disponível em: http://www.idec.org.br/uploads/ revistas_materias/pdfs/2005-02-ed85-capa-frangos.pdf, Acesso em 02 mar. 2014.

JAMES, C.; VINCENT, C.; ANDRADE LIMA, T. I.; JAMES, S. J. The primary chilling of poultry carcasses - a review. International Journal of Refrigeration, v. 29, n. 6, p.847-862, 2006.

KATO, T.; BARBOSA, C. F.; IDA, E. I.; SOARES, A. L.; SHIMOKOMAKI, M.; PEDRAO, M. R. Broiler chicken PSE (Pale, Soft, Exsudative) meat and water release during chicken carcass thawing and Brazilian legislation. Brazilian Archieves of Biology and Technology. v. 56, n. 6, p. 996-1001, 2013. não ser rara a ocorrência desse tipo de falhas tecnológicas e a presença dessa fraude em nosso país, inclusive em produtos que se encontram disponíveis para venda à população.

\section{Conclusões}

Pode-se concluir que $4,44 \%$ das amostras globais do monitoramento apresentaram-se fora do padrão legal determinado pelo MAPA. Ressalta-se que tal monitoramento deve se constituir em avaliação de rotina, com colheita de amostras prontas para a comercialização sem prévio aviso, como prática a salvaguardar os interesses dos consumidores e à coibição de fraudes intencionais, principalmente naqueles estabelecimentos que evidenciem valores frequentemente elevados.

MACHADO, F. M.; KATO, T.; PAIÃO, F. G.; SHIMOKOMAKI, M. Verificação do percentual de água perdida por descongelamento em frangos inteiros congelados comercializados na cidade de Londrina/PR.In: XVII SEMINÁRIO DE INICIAÇÃO CIENTÍFICA E TECNOLÓGICA DA UTFPR. 2012, Curitiba, Anais... Disponível em: http://conferencias.utfpr.edu.br/ocs/index.php/sicite/2012/ paper/viewFile/635/512, Acesso em 11 nov. 2013.

NEGRINI, E.; SOUZA, C. C.; FILGUEIRAS, C. T.; PIRES, V. S.; VIEIRA, F. A. F. Avaliação dos níveis de absorção de água em carcaças congeladas de frango no varejo alimentar da cidade de Campo Grande, MS. Ensaios e Ciência, v. 11, n. 1, p. 41-48, 2007.

R CORE TEAM. R: A language and environment for statistical computing. R Foundation for Statistical Computing, Vienna, Austria. URL http://www.R-project.org/, 2013.

SÁ, M. A. R.; SILVA, G. C.; COSTA, V. L. Determinação do percentual de água em carcaças de frangos congelados, comercializados no Município de Uberlândia, MG. Revista Higiene Alimentar, v. 21, n.152, p. 42-46, 2007.

SANTOS, D. V. S.; BARROS, L. S. S.; MASCARENHAS, M. T. L. V.; LIMA, K. C. Evaluation of Drip Test Sampling Plan in Carcasses of Frozen Broilers. International Journal of Poultry Science, v.12, n.11, p.628-634, 2013.

UBABEF, União Brasileira de Avicultura. Relatório Anual 2013. Disponível em: http://www.ubabef.com.br/files/publicacoes/732e6 7e684103de4a2117dda9ddd280a.pdf, Acesso em 02 mar 2014. 